\title{
INSTITUTIONS FOR THE TUBERCULOUS.
}

\section{THE LOOMIS SANATORIUM.}

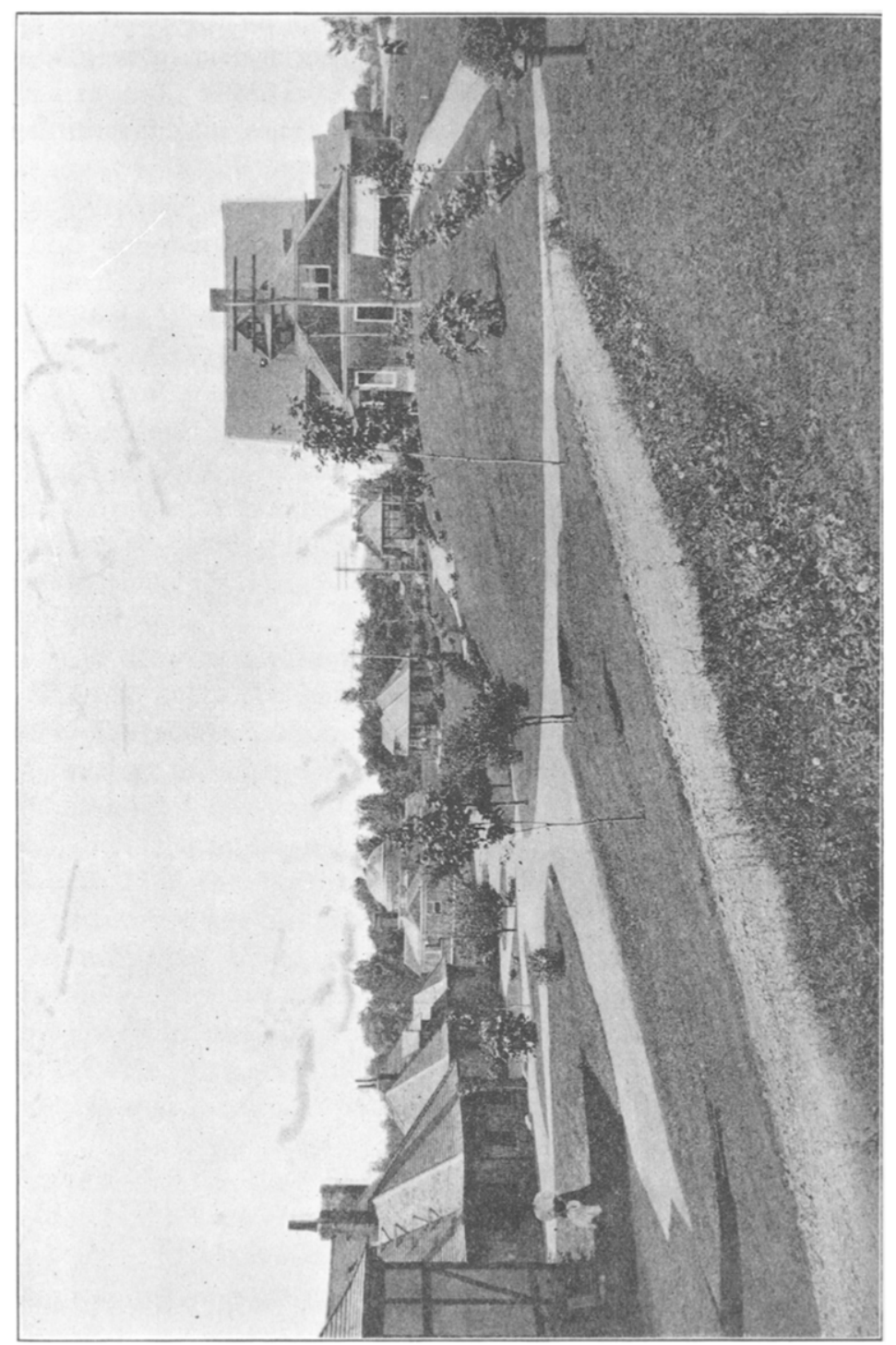

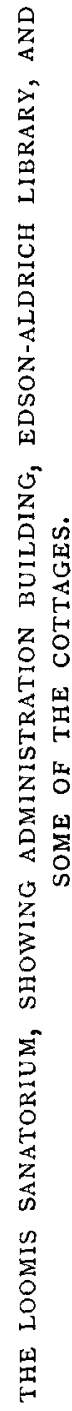

THE Loomis Sanatorium, established in $\mathbf{1} 896$, is on Liberty Heights, Sullivan County, New York, in a picturesque and healthful country, 
2,000 feet above sea-level and four hours' journey from New York City. The sanatorium property consists of 500 acres of land partially cleared and cultivated, that portion immediately surrounding the cottages being laid out as a park. A reception hospital, fourteen cottages, an administration building, a casino, a library, and a chapel comprise the principal buildings. Acute and advanced cases of tuberculosis are cared for in the reception hospital ; but all patients entering the institution must pass through this hospital, where their exact condition is accurately ascertained, and from whence they are assigned to cottages when no longer in need of constant observation. There are four private cottages, each in charge of a nurse. These comprise independent units. Patients in other cottages, where the rates are lower, take their meals in the administration building. Inclusive of the reception hospital, there is accommodation for 125 patients and ample provision for visitors. In addition to the main sanatorium, there is an intermediate division with fourteen beds for patients of limited means. There is also, an annex, accommodating forty patients, where the rate is nominal, and where twenty-three free beds are maintained. The institution is under the direction of a physician-inchief, with a staff of assistants and a corps of specially trained nurses. There is also an advisory board of non-resident physicians.

\section{HeRbert Maxon King, M.D.,} Physician-in-Chief.

\section{THE ADIRONDACK COTTAGE SANITARIUM.}

The Adirondack Cottage Sanitarium, on the northern slope of a wooded hillside, well protected from wind, at Trudeau, one mile north of Saranac Lake, in the county of New York, was founded by E. L. Trudeau in I 884 for patients who could not afford otherwise to remain in the Adirondacks. It consists of twenty wooden, brick, or stone cottages, given by wealthy patrons, designed usually for four patients, each having a separate room, and so arranged that each room opens on a spacious, sunny, but well-protected veranda, upon which the bed may be rolled; a chapel, a library, an infirmary; a medical pavilion, containing eight rooms for new patients, who spend two weeks here before going to the cottages; as well as an excellent laboratory, ray-room, hydro-therapeutic room, drug-room, examining offices, medical library, record-room, and fire-proof vault for records ; an open-air workshop, an open-air assembly or amusement hall, and many other buildings, all grouped about a central administration building, containing the administration offices, the dining-room, the general and diet kitchens, as well as rooms for some members of the staff and for some patients. There are no Liegehallen. The buildings are heated by hot water, lighted by electricity; the floors are hard wood (chiefly native maple), and the walls tinted with a light water or oil paint. The medical staff consists of three resident physicians and four nurses, all of whom have had pulmonary tuberculosis. The records are very complete. Careful monthly records and examinations are made. Each patient is requested on the anniversary of his discharge, the average residence being seven months, to fill out a blank, varying from year to year, and the replies 